\title{
Expositive Acts on Instagram: Knowing What People Intent to "Write" on their Captions through Pragmatics Perspective
}

\author{
Amirudin Amirudin ${ }^{1 *}$, Sulis Triyono ${ }^{2}$ \\ ${ }^{1}$ Applied Linguistics Post-graduate Program, Universitas Negeri Yogyakarta, Yogyakarta 55281, Indonesia \\ ${ }^{2}$ Faculty of Language and Arts, Universitas Negeri Yogyakarta, Yogyakarta 55281, Indoensia \\ Corresponding Author: Amirudin Amirudin, E-mail: amhier100@gmail.com
}

\section{ARTICLE INFO}

Article history

Received: January 27, 2018

Accepted: March 21, 2018

Published: July 01, 2018

Volume: 7 Issue: 4

Advance access: May 2018

Conflicts of interest: None

Funding: None

\begin{abstract}
Instagram as one of the famous social network sites in this century is as one way to share various kinds of general information and to present our activities, events, achievements, vacations, and so forth. The present study explored expositive acts presented in the caption of Instagram-posting by Indonesian users. It is interesting that expositive acts used are to emphasize self-presentation on their posting. 734 photo-posting with caption from 15 participants were found. The expositive acts performed by the participants were classified based on the kinds of expositive acts as proposed by Austin (1962). The factors initiating each kind of expositive acts were described. The representation of self-presentation on expositive acts was discussed. The present study found ten kinds of expositive acts which were also identified as the communicative intention presented in their Intagram-posting with caption, namely: apprising, describing, affirming, supposing, remarking, informing, postulating, confirming, arguing, and telling. Finally, the present study offer implication for further study that the caption used in this social medium is as another valuable aspect in Instagram for emphasizing self-presentation phenomena, in which this caption is also incorporated with communicative intention by the users implicitly or explicitly addressed to others.
\end{abstract}

Key words: Pragmatic Analysis, Speech Act, Expositive Act, Social Network Site, Instagram

\section{INTRODUCTION}

Nowadays, Social Network Sites (SNSs) grow widely following the development of the technology. People are now very familiar with Facebook, Twitter, Instagram, and so forth. It is found that SNSs are very beneficial for individual or communal needs. SNSs are used to connect a wide number of users to share information and to build social network interaction each others, various types of individuals, groups, communities, and organizations. Sometimes, it is found that they commonly express their own information, emotion, feeling through SNSs to appreciate what they have done in real life. It is also commonly found that one person will have at least one or more SNS's account as used for their daily life. Teenagers are the most addicted object by these SNSs.

Instagram as one of the famous social network sites in this century is considered as one way to explore about 'what we have', 'what we do', 'what other people have', and 'what other people do'. It is not only about updating one or some interested pictures but also providing writing post for emphasizing the exploration of our own information or others. It is considered as a medium of worth lan- guage phenomena: what they write in the 'caption' column can be related to some aspect, such as culture, news, social phenomena, education, religion, knowledge, and even personal information. This personal information aspect will be the focus of the present study, established as self-presentation in which it is considered as pragmatic phenomena as expositive acts.

Studies exploring about Instagram as social phenomena has extended these over the last years. As a study was done by Ferwerda et al. (2015), in which this study explored the personality traits of the users through the picture uploaded correlating to the filter they used. This study found various kinds of picture features by extracting 22,398 pictures from 113 participants and emphasized that there is a relationship between personality traits and the way users want to make their picture look (Ferwerda et al., 2015). It is understood that people will express their personality through pictures edited by some filter features provided by Instagram. Yet, pictures are not the only things that they share on Instagram. Some pictures would be given with 'text' called 'caption' as the complement of the situation and the purpose of the pictures. This text 
is seen as another self-intended presentation by the users for conveying personality feeling, emotion, information, and so forth.

Other studies done by Andalibi et al. (2017) and Jackson et al. (2017). These studies explored the phenomena of self-disclosures by the users in case of depression and criticism. The researchers examined the responses and social supports given to the depressed image-sharing and emotional response regarding to criticism. It is reported that Instagram is used as a tool to participate in social reciprocity and story-sharing about difficult experiences, and this research emphasized that numerous evidence of social support, a sense of community, little attack for dangerous disease, and support for pro-disease behaviors are found related to the depressed image-sharing. And, it is also shed light on responses given to the photo-sharing regarding to criticism, positive and negative responses, in which these responses are found depending on the personality of the users. These studies are a kind of self-presentation analysis in which the users share their pictures to disclose difficult emotion, depression, sensitive self-information, and so forth. The researchers analyzed the correlation between the pictures shared to the comment given as considered: responses or social support. One aspect was forgotten is that self-disclosures can be also traced by the 'text' given as the 'caption'. This text is as additional information related to the picture shared. Thus, it comes to draw an argument that the 'texts' conveyed are phenomena of self-presentations expressed by Instagram users through expositive acts.

More studies done by exploring self-presentation contained in this picture-shared Social network sites. Narcissisms concerning body image satisfaction among youth are explored (Moon et al. 2016; Ahadzadeh et al. 2017; Fardouly et al., 2017). These studies claim that Instagram users intend to show self-promotion related to the body image they present. They state that higher intention of narcissisms is shown in the intensity for updating their profile picture and the intensity for using Instagram. They also revealed that image shared in Instagram likely influence other users' appearance and beliefs. Sometimes it is also found that images are presented for emphasizing self-schema, self-discrepancy, and self-esteem. Another aspect ignored in these studies is the texts presented espousing the images may emphasize these self-presentations by the users. The texts support the narcissisms and self-presentations by showing these intentions verbally. The texts are performed as expositive acts in pragmatic perspective.

Against the background, the present study has two points to be explored: what kind of expositive acts performed by Instagram users in their photo-posting? And how the expositive acts represent people's self-presentation from the perspective of pragmatics? These expositive acts are presented in the caption of the photos. The photos espousing the posting were one of the contexts that can be considered to support the analysis. It becomes interesting to be investigated because expositive acts are related to pragmatics aspect, in which those are considered as speech act phenomena: the users intend to deliver information, personally or generally, as self-presentation literally or non-literally to the readers. Three goals were intended to be presented: describing the factors initiating each kind of expositive acts, classifying the kinds of expositive acts performed in their posting, and further discussion is given to reveal how expositive acts represent users' self-presentation.

The present study is expected to be beneficial for the Instagram users: identifying self-presentations from other users is important for knowing the intrigues. It is also expected to be useful for others researchers who have the same interested that language phenomena are growing fast especially in social network sites. It is also expected to emphasize that the use of discourse (written or spoken) is intended to convey something rather than only to say or to write something.

\section{THEORETICAL BACKGROUND}

\section{Speech Acts in Pragmatics}

The development of technology has given remarkable influences to language study. Nowadays, people have numerous tools of communication in daily life, in which these tools also increase language phenomena used in society. One of the tools for communicating is using the platform of social media. The use of social media draw an idea: the variety of users creates variety of language use in different contexts and purposes. Thus, this idea has become interesting consideration by many researchers in exploring language phenomena appearing in the use of social media (social network sites), particularly from pragmatics point of view, as the intent to be done in the present study.

A pragmatic study makes clear that in communication people not only have a literal text, but also a meaning beyond the literal text conveyed by a speaker or writer (Igwedibia, 2018). The meaning conveyed is interpreted by a listener or reader based on the context constraining the text (oral or written). In other words, when we talk about pragmatics, we are simply talking about meaning beyond the linguistic data. Further, as defined by Fromkin et al (2014, p. 165), literal text is not the only sort of text people use when people use language to communicate with others. A text has meaning called "extra-truth-conditional". It comes as a result of how a speaker uses the literal text in conversation, or as a part of discourse. The study of this "extra-truth-conditional" meaning is pragmatics. Pragmatics also allows us "to see how language is used in interesting and social ways".

A study about speech acts is a branch of pragmatic studies as it deals with an 'act' in making an utterance or sentence (Koussouhon \& Dadjo, 2016). They are language phenomena appearing surrounding society. They were found in memes as social network sites phenomena (Grundlingh, 2017). They were analyzed on the use of conversational style on Twitter (Scott, 2015). They are 
shedded light on Facebook post-telling (Farina, 2015). They were also explored in Facebook status messages (Carr, 2012). In the present study, the researcher intends to explore the use of speech acts performed in Instagram, particularly the use of expositive acts expressed as self-presentation.

As described by Yule (2010, p. 133), speech act is the study focusing on "what speakers mean". The communication is emphasized on "besides recognizing the meaning of words in an utterance, the interlocutors must also recognize what speakers mean by their utterances". When people communicate with a text, interpreting the meaning is considered by knowing the word or the utterances conveyed to deliver the message and relying on what we think about the speakers' intention in communicating the message. Those are how speech acts understood. Further, speech acts, as asserted by Grunberg (2011), are two activities happened simultaneously: saying and doing, that a speaker who conveys an utterance is amounted to a particular doing. As also defined by Fromkin et al (2014, p. 177), speech acts tell us how people use language to do things, such as: informing, asserting, committing, and so forth. To correlate, texts provided as caption in Instagram are kinds of users' intention to communicate to the others. The communication implicitly or explicitly conveys something related to self-presentation, involve; self-information, pride, achievement, positive response intention, telling, and so on.

As claimed by Austin (1962), when people convey utterances, they are not only saying something, but they intend to do something, for instance, promising, apologizing, commanding, and so on. Austin defined speech acts into three forms: (1), locutionary acts which are the presentation of the sounds and words or "performing the act of saying something'. (2), illocutionary acts which are the act of saying something or 'performing an act in saying something'. In other words, illocutionary acts refer to a speaker's intention (or writer) in conveying an utterance or sentence. (3), perlocutionary acts which are the effect of saying something (intentionally or unintentionally) or 'performing an act by saying something'.

Five kinds of illocutionary acts are proposed by Austin (1962). First, expositives, which are statements or delivering facts, emphasizing the interlocutors to form or attend a belief, for examples; stating, boasting, complaining, affirming, denying, emphasizing, illustrating, and so on. Second, exercitives, in which the speakers intend for getting the interlocutors to do something, for examples; ordering, commanding, requesting, and so on. Third, behabitives, in which the speakers convey their feeling toward the interlocutors, for examples; thanking, congratulating, pardoning, agreeing, greeting and so on. Fourth, commissives, in which the speakers give commitment to do something regarding to the interlocutor, for examples; promising, rowing, offering, and so on. Fifth, verdictives, in which the speakers determine what the case is in an institution or change an institutional state of affairs regarding to the interlocutors, for examples; resigning, dismissing, naming, sentencing, and so on. Here, as suggested in the present study, kinds of Expositives are expected to be found in Instagram posting, in case of Indonesian users.

\section{Expositive Acts}

As the part of illocutionary acts, Kissine (2009) defined expositive acts (which is also claimed as assertive) as representation of states of affairs. The point of expositive acts is "to represent how the world is", that the content of a 'thing' is true. The utterance conveyed is intended to make a belief that the content is strong to be a truth. A speaker or writer codes a statement to emphasize that his or her idea is strong to be accepted.

As stated by Oishi and Fetzer (2016), expositive acts as proposed by Austin are a kind of higher-level of illocutionary acts which sheds light on the intention of interpreting speech acts and their linguistic realizations in language phenomena. Expositive acts are performed in acts of exposition concerning the expounding of views, conveying an argument, and emphasizing an idea. In this case, people share picture on Instagram while giving texts as the caption are assumed that they express self-exposition as called self-presentation. This self-presentation is verbally conveyed in form of caption as mentioned above. Pragmatic analysis is used to trace this intended self-presentation as expositive acts performed by the users of Instagram.

As provided by Austin, here will be given more lists of expositive acts as follows:

Table 1. Kinds of expositive acts by Austin (1962)

\begin{tabular}{ll}
\hline Category & Kinds of expositive acts \\
\hline Statement & $\begin{array}{l}\text { Affirming, denying, stating, describing, } \\
\text { classing, identifying }\end{array}$ \\
Concession & $\begin{array}{l}\text { Remarking, mentioning, interposing } \\
\text { Informing, apprising, telling, answering, } \\
\text { Information }\end{array}$ \\
rejoining, asking \\
Testimony & $\begin{array}{l}\text { Testifying, reporting, swearing, } \\
\text { conjecturing, doubting, knowing, believing, } \\
\text { supposing }\end{array}$ \\
Acceptance & $\begin{array}{l}\text { Accepting, conceding, withdrawing, } \\
\text { agreeing, scrupling to, objecting to, }\end{array}$ \\
& $\begin{array}{l}\text { adhering to, recognizing, repudiating } \\
\text { Confirmation }\end{array}$ \\
& $\begin{array}{l}\text { Postulating, deducing, arguing, neglecting, } \\
\text { emphasizing }\end{array}$ \\
\hline
\end{tabular}

In summary, the expositive acts proposed by Austin (1962) as presented in the above table is as the first consideration to explore the expositive acts performed by Instagram users in their photo-posting which is espoused by caption, whereas the photo-posting without caption is ignored. The analysis of these expositive acts is established by pragmatic analysis in which the communicative intention performed in the caption is related to the context beyond the structure of the language use. 


\section{Instagram and Social Network Sites}

Over the last few years, Social Network Sites (SNSs) have grown widely following the development of the technology and become the primary communication tool in which people use these SNSs for developing their personal online network (Lee et al., 2015). The variety of SNSs, such as Facebook, Twitter, and Instagram, are familiarly known by wide community around the world. As reported by Pittman and Reich (2016) that the development of these numerous SNSs makes the platforms of communication become more effortless and all over the place. It has been demonstrated that SNSs are very beneficial for individual or communal needs. Thereby, it is commonly found that one person will have at least one or more SNS's account as used for their daily life.

The development of social network sites can generally be determined as applications that facilitate users for producing and sharing numerous contents through networks. As defined by Pittman \& Reich (2016) that the forms of these social network sites have transformed how people associate each others, and how society are more linked with each other than even before, and young generations are the most enamored users. In other words, social network sites are mostly used to be connected with a number of users around to share information, events, interests, and other contents, and these are also functioned to build more relation to various kinds of individuals, groups, communities, and organizations. In the use of these social media, it is commonly found that most users express their activities, emotions, feeling, and other events related to self-information through these social media in order to show and appreciate what they have done in offline situations. Therefore, the issue of self-presentation in these social media is the most interesting and developing territory done by many researchers.

Formerly created in 2010, Instagram as one of famous social networks sites is an application of mobile photo-sharing and determined as the fastest growing social medium among other social network sites (Sheldon \& Bryant, 2016). As demonstrated by Lee et al. (2015), Instagram is as a medium that facilitates users to save and to change an image into a memory in order to keep it around forever. Unlike other social network sites, the main share-contents of Instagram is image, then 'text' is as complementary content. In other hand, Instagram users set down their experiences through photograph and short videos, and supported by captions for emphasizing the information presented. Thus, many researchers focus on the image-shared to explore the phenomena of self-presentation by the users, though the caption used as the complementary information is valuable phenomena to be explored by knowing what is trying to be communicated through these 'text' by the users to others. Thereby, Instagram is not only about what is trying to be shared by photo-posting, but also what is trying to be emphasized by 'text' written as caption. The phenomena of self-presen- tation appear in the photo shared and emphasized by the captions written, in form of expositive acts.

The use of Instagram is now developed into many functions. It also draws interest from different of scholars to explore the phenomena appears on it nowadays. The issue of self-presentations performed in this social medium concerning narcissisms, criticisms, disclosures, depressions, identity performances, etc., have been reported by many researchers (Schwartz and Halegoua, 2014; Smith and Sanderson, 2015; Moon et al., 2016; Jackson and Luchner, 2017; Andalibi, Ozturk, and Forte, 2017). Another interesting issue from this social medium is the influence of what people post in their Instagram to users' buying behavior and social identification that has been demonstrated by Djafarova and Rushworth (2017), in which young women is the most influenced users regarding their purchase decisions. Furthermore, the current issue explored by researchers who are interested in Instagram is related to political expression and participation through users' photo-posting (Zuniga, Molyneux, and Zheng, 2014; Mahoney et al., 2016; Filimonov, Russmann, and Svensson, 2016), in which it is found that this social medium has become a tool for political expression and participations. Farther, it is also reported that this social medium has been used as a propaganda tool (Kohn, 2015), where people can perform their tendency to influence other users through their photo-posting. After all, the main function of this social medium and other social network sites is as social interaction (Lee et al., 2015).

To sum up, in refers to the phenomena of Instagram as illustrated earlier, those come to draw researcher's curiosity to explore another phenomenon from Instagram that has been, as the researcher notices, not reported yet, i.e. exploring the communicative intention, in the forms of expositive acts, performed by users in Instagram photo captions which can be established through pragmatic perspective. These captions, however, are another important aspect that users emphasize on their photo-posting as self-presentation addressed to other users. Therefore, the present study intended to track the expositive acts performed by users on their photo-sharing with caption through pragmatic analysis.

\section{METHOD}

\section{Participants}

This study takes convenience sample of 15 students (10 female participants and 5 male participants) recruited randomly from Applied Linguistics class of post-graduate program, Yogyakarta State University - Indonesia. These participants are Instagram users in which they use Instagram intently, though they do not upload pictures regularly. It was found that most of their pictures uploaded by giving "texts" as for emphasizing self-presentation intended in their pictures. These "texts" are called captions. Meanwhile, some pictures were found without caption. Yet, the focus of this study is 
the pictures with captions uploaded by the users. All initial participants were given course extra credit for their participation.

\section{Data Collection}

After considering the participants, the data were collected by using researcher's Instagram account. The participants were told that their accounts would be observed and their uploaded pictures would be taken as the data of the present study. The data were collected during ten months, in January $1^{\text {st }}-$ October $31^{\text {th }} 2017$. The main data of the present study was the "texts" as caption in their photo-posting, written in English, Indonesia, Javanese, and Acenese language, given for emphasizing self-presentation performed in the pictures uploaded. Whereas, the pictures were as the supporting contexts for classifying kinds of expositive acts performed in each caption. Simak method was used to collect the data in which the captions were red repeatedly for getting valid data of expositive acts performed in each caption (Sudaryanto, 2015). As the result from observing the participants, 734 captions were found. At the same time, 65 pictures found without caption were unconsidered as the data of the present study.

\section{Data Analysis}

In order to analyze the data, the researcher used Padan method (Sudaryanto, 2015) in which the data were analyzed through pragmatics perspective. There were some focuses of analyzing the data: first, considering the frequency of the data from each participant. Second, identifying the kinds of expositive acts performed in the captions in which these expositive acts are as proposed by Austin (1962) as described above (Affirming, denying, stating, describing, identifying, informing, arguing, emphasizing, mentioning, testifying, reporting, and so forth), and describing the factor initiating each kind of expositive acts presented in the captions. Third, classifying the kinds of expositive acts found in the captions from the participants.

\section{FINDINGS}

The present study aimed to explore expositive acts performed in Instagram-posting by Indonesian users using pragmatic analysis, in which these expositive acts were presented in their captions as another way to perform self-presentation. The kinds of expositive acts are classified based on the notion of expositive acts proposed by Austin (1962). The factors initiating each kind of expositive acts are described.

The analysis of 734 'Instagram captions' reveals that ten kinds of expositive acts were performed by the participants, i.e.; apprising, affirming, supposition, remarking, informing, postulating, confirming, arguing, telling, and describing. Further presentation is given as follows:

\section{Factor Description of Expositive Acts}

The factors initiating these ten kinds of expositive acts were established by analyzing the captions through pragmatic perspective in which the texts used by the participants are correlated to the social phenomena as the primary contexts and using the photos espousing the captions as secondary context to strengthen the result of analysis. The following table 2 is the description of the factors initiating each kind of expositive acts that emphasize self-presentation performed by the participants.

Table 2. The factors initiating each kind of expositive acts performed by the participants

Kinds of $\quad$ Factors
expositive
acts

Apprising

Describing

Affirming

Supposing

Remarking

Informing

Postulating

Confirming

Arguing

Telling
Which is performed by instagram users to give information to someone or other users about his or her events, vacations, physical experiences, and other daily activities.

Which is performed to tell someone the appearance, sound, smell, events, form, feature, etc., of someone or something (friends, cook, fashion, and scenery).

Which is performed to show a strong belief in or dedication to something, such as an important idea, faith, and principle.

Which is performed to bring an idea or theory that is believed to be true, though no proof is found, such as: predicting an issue (politic, religion, and tribe), an event, and information.

Which is performed to say or to express an opinion or idea (a tendency to advise with strong idea and opinion).

Which is performed to be or provide the essential quality of something, such as: family, event, tourism object, and personal stuff.

Which is performed to suggest something, such as: theory, quote, and holy verse.

Which is performed to tell other users that something has definitely happened or is going to happen; to make something definite or official, such as: news, issue, and accident.

Which is performed to give reasons for or against something; to say or write things in order to change someone's opinion about what is true and what should be done

Which is done to express feeling to other users, such as sadness, happiness, madness, disappointment, and failure. 


\section{Expositive Act Classification}

The 734 used as the data of the present study are classified based on the ten kinds of expositive acts described above. The frequency and the percentage are also illustrated for ensuring the distribution of the data, as follows:

\section{DISCUSSION}

The results of exploring the expositive acts performed by Instagram users in the caption of their photo-posting are the description of the factors initiating each kind of expositive acts and the classification of kinds of expositive acts. 734 data were found from 15 participants as presented in Table 3. Then, 10 kinds of expositive acts were found after classifying the data, in which the distribution of the expositive acts is various. These ten kinds of expositive acts are related to the expositive acts as proposed by Austin (1962) and correspond to the study reported by Oishi and Fetzer (2016) that expositive acts are a part of speech acts which are related to self-exposition (as another term of self-presentaion) by speaker in conveying utterances, in this case is Instagram users in which they expose various interesting things that they have through photo-sharing emphasized by captions. At last, this section will discuss further regarding a question left in the previous introduction that is how expositive acts represent people's intent to express self-presentation through captions.

As the main focus of the present study is to explore the expositive acts phenomena on Instagram, in which these expositive acts are the communicative intention detected by pragmatic analysis, it is emphasized that Instagram users have intention to communicate to other users implicitly or explicitly, whether for self-presentation or for another ten- dency. This communicative intention in social network sites, as a tool for social interaction, is mostly found in form of pragmatic strategies, namely: people do things with words, people do an act with language, for instances: informing, telling, arguing, confirming, describing, and so on (Austin, 1962). As done by a number of researchers, these pragmatic phenomena have been shown by Carr et al. (2012) in their research about Speech acts performed in Facebook status messages. This also has been shown by Scott (2015) in his study about pragmatic phenomena in using hashtags on Twitter. It has been explored as well by Grundlingh (2017), which analyzed the use of speech acts in memes.

The next issue to be confirmed is that people use social network sites mostly present things about their selves regarding activities, events, feelings, possessions, vacations, fashions, faith, principles, family members, accidents, physical experiences, and so on (as called self-presentation), as illustrated on the factors initiating the expositive acts in the Table 2. A significant analysis and discussion on this issue was presented by Carr et al. (2012) in their study about speech acts performed in Facebook status by giving conclusion that the data from their participants showed that self-presentation were performed intentionally in Facebook status messages. Furthermore, it also has been reported by Nadkarni and Hofmann (2012) that generally people have two main motivations in using social network sites, namely: the need of belonging and the need for self-presentation. It also has been discussed well by Smith and Sanderson (2015) in their study about athlete self-presentation on Instagram, though the focus of this self-presentation analysis is on the photograph uploaded by the athlete in which the caption is analyzed separately and is considered as not necessary data, in other hand the caption is somewhat abandoned, while the

Table 3. Classification of the data into ten kinds of expositive acts performed by the participants.

\begin{tabular}{|c|c|c|c|c|c|c|c|c|c|c|c|c|}
\hline \multirow[t]{2}{*}{ Participants } & \multicolumn{10}{|c|}{ Kinds of expositive acts } & \multirow[t]{2}{*}{ Frequency } & \multirow[t]{2}{*}{ Percentage } \\
\hline & APP & AFF & SUP & REM & INF & POS & $\mathrm{CON}$ & ARG & TEL & DES & & \\
\hline P-1 F & 1 & 2 & - & - & - & - & - & - & - & 5 & 8 & 1.08 \\
\hline P-2 F & 3 & 5 & 3 & 3 & 4 & 4 & 1 & - & - & 8 & 31 & 4.22 \\
\hline P-3 F & 12 & 4 & - & 2 & - & 1 & - & 2 & - & 6 & 27 & 3.68 \\
\hline P-4 M & 34 & 9 & 3 & 5 & 4 & 1 & - & 1 & - & - & 57 & 7.77 \\
\hline P-5 F & 24 & 5 & - & 6 & 8 & 4 & - & - & - & 3 & 50 & 6.81 \\
\hline P-6 F & 7 & 2 & - & 4 & - & - & - & - & 7 & - & 20 & 2.72 \\
\hline P-7 F & 19 & 6 & 2 & 6 & 2 & - & - & - & 35 & - & 70 & 9.53 \\
\hline P-8 F & 16 & 7 & - & 3 & - & 15 & - & - & 5 & - & 46 & 6.27 \\
\hline P-9 F & 4 & 1 & - & 2 & - & 1 & - & - & 20 & - & 28 & 3.81 \\
\hline P-10 F & 9 & 5 & - & 3 & 6 & - & - & - & 24 & - & 47 & 6.40 \\
\hline P-11 F & 4 & 1 & - & 4 & 9 & 7 & - & - & 4 & - & 29 & 3.95 \\
\hline P-12 M & 40 & 1 & - & 1 & 42 & 2 & 1 & - & - & - & 87 & 11.85 \\
\hline P-13 M & 102 & - & - & 1 & 23 & - & - & - & - & - & 126 & 17.17 \\
\hline P-14 M & - & 2 & - & 2 & 4 & 3 & - & - & - & 3 & 14 & 1.90 \\
\hline P-15 M & 18 & 1 & - & 8 & 59 & - & 2 & - & - & 6 & 94 & 12.80 \\
\hline TOTAL & 293 & 51 & 8 & 50 & 161 & 38 & 4 & 3 & 95 & 31 & 734 & 100 \\
\hline
\end{tabular}

P-(n) F: Female participant, P-(n) M: Male participant, APP: Apprising, AFF: Affirming, SUP: Supposing, REM: Remarking,

INF: informing, POS: Postulating, CON: Confirming, ARG: Arguing, TEL: Telling, DES: Describing. 
caption in the present study is valuable data for analyzing the expositive acts using pragmatic analysis to find out the implicit intention by uploading the photograph.

In refers to the result as presented in the Table 3, it shows that the richest data is the performance of apprising act in which this act refers to the participant's presentations for giving information, closely related to self-exposing, about his or her events, vacations, and daily activities, to someone or other users. This act was performed by participants in 293 captions. The following example is the data of the present study:

(1) Nunggu dosen nggak masuk2 kelas, paling enak emangsambilngemil@misterpotato_id,renyahh dan gurihh looohh. iya nggak yun??

Example 1 is a caption that is about a university student waiting for her lecturer in the classroom in which the lecturer would come late. The apprising act was given for emphasizing her activity in her college. It is obvious that such caption will strengthen any kind of picture shared by the users regarding his or her self-presentation. The photo shared would not clarify what the user was doing without this caption. In other words, this caption ensured other users regarding her activity. As mentioned earlier, the act of apprising is related to participants' narcissism as has been discussed incredibly by Moon et al. (2016) that individuals who have higher in narcissism tends to post self-presented photos more often on Instagram related to his or her 'things'. Though, the focus of this previous study is totally on the photos posted by their participants, it seems that they neglected another aspect of Instagram, i.e. the caption. However, the captions are valuable data to be analyzed regarding narcissism as found in the present study.

The second dominant motive as presented in the result of classifying the data is reflected as informing act performed by 161 captions. This act is related to the intent of users to share certain information, such as: family, event, tourism object, and personal stuff.

(2) Welcome to the world, my new gorgeous baby is a boy. I hope I could see you soon as human possible.

The example 2 is a data of an act of informing. This caption was conveyed to give more explanation regarding his picture of his new nephew shared on Instagram. The act was performed to inform other users about his new family. The caption was given obviously to emphasize his self presentation on his new family member.

The third interesting result as presented in Table 3 is telling act. This act is conveyed by the participants in 95 captions. Telling is conveyed to express feeling: sadness, happiness, madness, disappointment, and failure

(3) Lebih baik diam dan pergi daripada bicara tapi menyakitkan. Lebih baik muram daripada senyum tapi cumin pura-pura... Tidak semua harus dikatakan panjang lebar agar mengerti, cukup rasakan apa yang sebenarnya terjadi.

The example 3 is given for clarifying the result of telling as another way performed by the participants for self-presentation. This caption is about user's disappointment in love relationship. This act of telling was conveyed to tell other users regarding her feeling that she had become quiet and grim woman, that she could not talk any longer about her sadness to the man she loved. In case of self-presentation, the photo that she shared absolutely "can speak louder than words" as stated by Lee et al, (2015), but we cannot ignore that words can talk deeper. This act is found in this Instagram, though it is also found in other social network sites as reported by Farina (2015) who has analyzed the pragmatic perspective on Facebook-status posting, in which she found that Facebook users have tendency to post status about telling: announcements and stories. It comes to be concluded that people have this kind of act in using social network sites verbally (in form of captions) or non-verbally (in form of pictures or photos).

The next expositive act tracked from the caption analysis which is as the motive presented by the participants is affirming and remarking acts with 51 and 50 captions illustrated in Table 3. As demonstrated in the factor description Table 2, affirming act is related to self-expression about principle and faith (who I really am), whereas, remarking act is related to users' expression in form of idea or opinion with tendency to advise other users. Such act of remarking conveyed by the participants is to express that something is true from his or her perspective.

(4) Semua skenarionya adalah ketetapan terindah.

(5) Jangan ragu melepas merpati untuk terbang. Karna yang terbaik akan selalu pulang.

The example 4 is about user's faith of God's scenario. This act is for affirming that he (the user) believed that God has made the best scenario for his life. This act clarifies a self-presentation performed by Instagram users through their captions regarding users' faith and belief. Whereas, example 5 is given to emphasize a self-presentation through an expositive act in their photo captions, in form of remarking act. The example given is about her idea (Instagram user) which says that a good man is like a dove that will always come back in a proper time. This caption presented her idea which had tendency to advice other users and to clarify that this act is as user's self-presentation regarding her idea of love story. To correlate, this corresponds to the statement reported by Lee et al. (2015) that another motive by Instagram users to share their photos regarding self-presentation is for: expressing idea and opinion, expressing actual self, and being noticed by others. Though, in the present study, these tendencies are found by analyzing the implicit meaning conveyed by the users in their captions through pragmatic point of view.

(6) Still don't quite understand why some people got so enraged when I upload this kind of photos around this hour... strawberry cheese cake which isn't my order, but it sure seems tasty with its fluffy cheesecake encased in nicely- torched cream. Offering caramelized touch on its soft brown-ish presentation. And not to forget the shiny strawberry with some kind of sweet sauce poured over it. La delicatessen

(7) Beneran ada.

(8) - we can't change the world but we can help it - \#quoteoftheday

(9) Selamat berkarya di tempat baru ayah. Dr. Abdul Kahar, M.pd. dari ayah untuk kami, dari kami untuk negeri, ayah tetap teladan kami \#tetapberkaryahayah.

(10) Temen gila pas jaman PPL, akhirnya kemarin dia ke jogja setelah 2 tahun nggak ketemu, taukan siapa yang gendutan. 
The example 6 is to clarify the act of describing which is related to users' motive to share various things from offline life on Instagram, then these 'things' are described by caption, such as: food, fashion, and scenery. This example is about a food description. The example 7 is to confirm the act of supposing which is related to users' tendency to predict: various issues in real life (politic, religion, and diversity of tribe), events, and information. While, this example is about his prediction (Instagram user) of a book he posted that said a human like an angel with pure eyes, then the caption is given as his suppositional idea, which said "that's true", to support the words from the book. The example 8 is to ensure that self-presentation is performed by Instagram users through expositive acts, particularly in form of Postulating act which is related to users' motive to share such theory, quote, and holy verse in their caption addressed to other users. The example 9 is to convey an act of confirming which is related to users' motive to create caption in their photo-posting for sharing something that is definitely happened or is going to happen in order to tell other users about probably precious information to be known. In this example, he confirmed information that a prominent figure had moved to another city for another job. We can intuitively conclude that he admired this figure. Therefore, his self-presentation is seen from his act in confirming a certain figure. The example 10 is to present her act (Instagram user) of arguing which is related to users' motive to use caption for arguing about her own information in order to change other users' opinion. This example says that she just met her old friend and some other friends said that she is fatter than this old friend, but by uploading their photo together, then she gave an argument in the caption that her friend should be fatter than her. To emphasize, those all motives mentioned earlier are found using pragmatic perspective, in which caption is as language phenomena that can be correlated to different context initiating users' intention in writing their words used for emphasizing self-presentation.

One point that is precious to be emphasized in this section is an interesting finding which contradicts to a previous research. The present study found that three male participants are the most active for sharing photos in Instagram as opposed to women participants which is the lowest is only sharing 8 photos for the considered period as illustrated in Table 1. In other words, no guarantee that gender will influence the motive of users to be active in Instagram. As mentioned earlier, this result likely contradicts to the study done by Sheldon and Bryant (2016) who emphasize that women are more potential to be active in sharing photo on Instagram rather than men. Though, this is caused by the tendency from each personality, in which, as tracked by analyzing the captions, apprising and informing acts are the richest data performed by these three participants. Therefore, motive for sharing photo on Instagram is likely not influenced by the gender, but more probably influenced by the needs from each personality of the users: different users have different needs in using Instagram both woman and man (Lee et al., 2015).

Finally, the expositive acts found in Instagram-posting by the participants in the present study clearly correspond to the self-presentation phenomena in social network sites, especially in Instagram, as discussed by many researchers previously. Yet, the new aspect that is given by the present study is the focus of the analysis, i.e. in form of verbal communication: texts, which are presented as captions, whereas the photos were used to emphasize and support the expositive acts found. Therefore, self-presentation phenomena are conveyed in their captions as well, in which the users perform an act verbally to other users explicitly or implicitly to communicate their stories from real life. This communication intention is the implication of pragmatic strategies.

Like other research, the present study remains limitations. In particular, the participants used are merely Indonesian so the findings will be implicated for Indonesian context, and would be strengthened in its conclusions by incorporating the response of other users. These limitations can be points of improvements for further research in this territory.

\section{CONCLUSION}

The development of social network sites gives influence to people around the world. Indonesia is one of enthusiastic countries which is influenced by the issue of social network sites fantastically, in this case is Instagram. The present study explored expositive acts on Instagram presented by Indonesian users in which the expositive acts are used as another way to perform self-presentation. The factors were described. The kinds of expositive acts were classified. The illustration of self-presentation conveyed through expositive acts was discussed.

Two points are offered to be emphasized in this conclusion regarding the phenomena of Instagram, namely: first, Instagram users clearly convey communication intention through captions in their photo-postings to other users, mostly in form of expositive acts. Ten kinds of expositive acts were found, namely: apprising, describing, affirming, supposing remarking, informing, postulating, confirming, arguing, and telling. Second, the expositive acts found are for emphasizing self-presentation due to the fact that the "act" found in this social network site are generally for sharing about personal "things" or personal information.

However, self-presentation as performed through photo-posting is indeed as users' motive to show what they have done in real life through online. People like sharing something in which Instagram is as one of the tools for this sharing-thing to other users, then, captions are used to strengthen the intended motive. To conclude, further research with wider contexts is suggested in order to track appropriately the communication intention performed in the caption on Instagram through pragmatic perspective, in which this communication intention is as another valuable aspect for establishing self-presentation by Instagram users in their photo-sharing.

\section{REFERENCES}

Ahadzadeh, A. S., Sharif, S. P., \& Ong, F. S. (2017). Self-schema and Self-Discrepancy Mediate the Influence of Instagram Usage on Body Image Satisfaction among Youth. Computers in Human Behavior, 68, 8-16. http://dx.doi.org/10.1016/j.chb.2016.11.011

Andalibi, N., Ozturk, P., \& Forte, A. (2017). Sensitive Self-disclosures, Responses, and Social Support on Instagram: The Case of \#Depression. CSCW, 1485-1500. http://dx.doi.org/10.1145/2998181.2998243 
Austin, J. L. (1962). How to Do Things with Words. London: Oxford University Press.

Carr, C. T., Schrock, D. B., \& Dauterman, P. (2012). Speech Acts Within Facebook Status Messages. Journal of Language and Social Psychology, 31 (2) 176-196. DOI: $10.1177 / 0261927 X 12438535$

Djafarova, E., \& Rushworth, C. (2017). Exploring the Credibility of Online Celebrities' Instagram Profile in Influencing the Purchase Desicions of Young Female Users. Computers in Human Behavior, 68, 1-7. http://dx.doi. org/10.1016/j.chb.2016.11.009

Fardouly, J., Willburger, B. K., \& Vartanian, L. R. (2017). Instagram Use and Young Women's Body Image Concerns and Self-objectification: Testing Mediational Pathways. New Media \& Society, 1-16. https://doi. org/10.1177/1461444817694499

Farina, M. (2015). Facebook First Telling. Journal of Pragmatics, 90, 1-11. http://dx.doi.org/10.1016/j.pragma.2015.10.005

Ferwerda, B., Schedi, M., \& Tkalcic, M. (2015). Predicting Personality Traits with Instagram Pictures. EMPIRE' 15, 16-20. http://dx.doi.org/10.1145/2809643.2809644

Filimonov, K., Russmann, U., \& Svensson, J. (2016). Picturing the Party: Instagram and Party Campaigning in the 2014 Swedish Elections. Social Media + Society, 1-11. DOI: $10.1177 / 2056305116662179$

Fromkin, V., Rodman, R., \& Hyams, N. (2011). An Introduction to Language. ( $9^{\text {th }}$ ed.). Boston: Wadsworth Cengage Learning, (Chapter 4).

Grunberg, A. (2011). Saying and Doing: Speech Actions, Speech Acts and Related Events. European Journal of Philosophy, 1-27. DOI: 10.1111/j.14680378.2011.00481.x

Grundlingh, L. (2017). Memes as Speech Acts. Social Semiotics, DOI: 10.1080/10350330.2017.1303020

Igwedibia, A. (2018). Grice's Conversational Implicature: A Pragmatics Analysis of Selected Poems of Audre Lorde. IJALEL, 7 (1), 120-129. http://dx.doi. org/10.7575/aiac.ijalel.v.7n.1p.120

Jackson, C. A., \& Luchner, A. F. (2017). Self-presentation Mediates the Relationship between Self-criticism and Emotional Response to Instagram Feedback. Personality and Individual Differences. http://dx.doi.org/10.1016/j. paid.2017.04.052

Kissine, M. (2009). Illocutionary Forces and What is Said. Mind \& Language, 24 (1), 122-138.

Kohn, A. (2015). Instagram as a Naturalized Propaganda Tool: The Israel Defense Forces Web Site and the Phenomenon of Shared Values. Convergence: The International Journal of Research into New Media Technologies, 1-17. DOI: 10.1177/1354856515592505

Koussouhon, L. A., \& Dadjo, S. D. Y. (2016). Pragmatic Analyses of President Goodluck Jonathan's Concession
Speech and General Muhammadu Buhari's Acceptance Speech: A Comparative Appraisal. IJALEL, 5 (4), 12-19. doi:10.7575/aiac.ijalel.v.5n.4p.12

Lee, E. et al. (2015). Picture Speak Louder than Words: Motivations for Using Instagram. Cyberpsychology, Behavior, and Social Networking, 18 (9), 552-556. DOI: 10.1089/cyber.2015.0157

Mahoney, J. et al. (2016). Constructing the Visual Online Political Self: An Analysis of Instagram Use by the Scottish Electorate. Politics on Social Media, 3339-3351. DOI: http://dx.doi.org/10.1145/2858036.2858160

Moon, J. H. et al. (2016). The Role of Narcissism in Self-promotion on Instagram. Personality and Individual Differences, 101, 22-25. http://dx.doi.org/10.1016/j. paid.2016.05.042

Nadkarni, A., \& Hofmann, S. G. (2012). Why do People Use Facebook? Personality and Individual Differences, 52 (3), 243-249. http://dx.doi.org/10.1016/j. paid.2011.11.007

Oishi, E., \& Fetzer, A. (2016). Expositives in Discourse. Journal of Pragmatics, 96, 49-59. http://dx.doi. org/10.1016/j.pragma.2016.03.005

Pittman, M., \& Reich, B. (2016). Social Media and Loneliness: Why an Instagram Picture may be Worth more than a Thousand Twitter Words. Computer in Human Behavior, 62, 155-167. http://dx.doi.org/10.1016/j. chb.2016.03.084

Sheldon, P., \& Bryant, K. (2016). Instagram: Motives for its Use and Relationship to Narcissism and Contextual Age. Computer in Human Behavior, 58, 89-97. http:// dx.doi.org/10.1016/j.chb.2015.12.059

Schwartz, R., \& Halegoua, G. R. (2014). The Spatial Self: Location-Based Identity Performance on Social Media. New Media \& Society, 1-18. DOI: $10.1177 / 1461444814531364$

Scott, K. (2015). The Pragmatics of Hastags: Inference and Conversational Style on Twitter. Journal of Pragmatics, 81, 8-20. http://dx.doi.org/10.1016/j.pragma.2015.03.015

Smith, L. R., \& Sanderson, J. (2015). I'm Going to Instagram It! An Analysis of Athlete Self-presentation on Instagram. Journal of Broadcasting \& Electronic Media, 59 (2), 342-358. DOI: 10.1080/08838151.2015.1029125

Sudaryanto, (2015). Metode dan Aneka Teknik Analisis Bahasa: Pengantar Penelitian Wahana Kebudayaan Secara Linguistik. Yogyakarta: Sanata Dharma University Press.

Yule, G. (2010). The Study of Language. ( $4^{\text {th }} \mathrm{ed}$.). New York: Cambridge University Press, (chapter 10).

Zuniga, H. G., Molyneux, L. \& Zheng, P. (2014). Social Media, Political Expression, and Political Participation: Panel Analysis of Lagged and Concurrent Relationships. Journal of Communication, 64, 612-634. DOI:10.1111/ jcom. 12103 